\title{
"A queda do céu" e o xamanismo no discurso de Davi Kopenawa
}

\section{"The Falling sky" and the shamanism on the speech of David Kopenawa}

\author{
Marla Elizabeth Almeida Reis ${ }^{1}$ \\ Raquel Wiggers ${ }^{2}$ \\ Solon Pessoa Godinho Neto ${ }^{3}$
}

Artigo recebido em: 10 de setembro de 2017. Artigo aprovado em: 20 de outubro de 2017.

\begin{abstract}
Resumo: As Sociedades Amazônicas possuem uma cosmologia que aloca em seus núcleos a corporalidade e a relação com os animais. O objetivo deste artigo, então, é clarificar as especificidades destas relações, as quais são baseadas no perspectivismo e multinaturalismo. Nesta esteira, pretende-se demonstrar como a figura do Xamã é importante e atua como mediador entre os diversos seres que habitam o mundo. Ao analisar os relatos de Davi Kopenawa, os quais foram escritos por Bruce Albert no livro "A queda do céu", espera-se revelar mais nuances sobre a cosmologia das sociedades Ameríndias.

Palavras-chave: Xamanismo, Perspectivismo, Multinaturalismo.
\end{abstract}

\begin{abstract}
The Amazon Societies have a cosmology that puts in the center their corporality and their conations with the animals. This article intents to clarify the specificities of those relations, which are based on perspectivism and in the multinaturalism. As regards, the goal is demonstrate how the figure of the Shaman is important and how he act as a mediator among the different being that live in the world. At the analysis of the narrative of Davi Kopenawa, which were written for Bruce Albert in the book "The Falling Sky", it intends to revel more nuances about the cosmology of the Amerindian societies.
\end{abstract}

Key Words: Shamanism, Perspectivism, Multinaturalism.

\section{Introdução}

A antropologia clássica não contempla em sua totalidade as continuidades e rupturas presentes nas sociedades indígenas sul-americanas. Conceitos como descendência e linhagens quando aplicados ao material etnográfico sul-americano - só evidenciam a fluidez dessas sociedades.

\footnotetext{
${ }^{1}$ Antropóloga, mestranda em Antropologia Social pela Universidade Federal do Amazonas - UFAM. Email: marla-reis@hotmail.com

${ }^{2}$ Doutora em Ciências Sociais pela UNICAMP, Docente vinculada à Universidade Federal do Amazonas/UFAM. E-mail: raquel-wiggers@gmail.com

${ }^{3}$ Bacharel em Direito pela Universidade Federal do Oeste do Pará/UFOPA. Pós-Graduando em Direito Penal e Criminologia pelo ICPC/UNINTER. E-mail: solongodinho@gmail.com
} 
Dessa forma, invés de tentar encaixar modelos trazidos da África, Mediterrâneo e Melanésia, ou tentar analisar as sociedades ameríndias pelas "ausências", construiu-se um modelo próprio, criado a partir do que é característico dessas sociedades, baseado no perspectivismo, construção do corpo e noção de pessoa. Segundo Viveiros de Castro o perspectivismo ameríndio é uma concepção comum aos povos do continente "segundo a qual o mundo é habitado por diferentes espécies de sujeitos ou pessoas, humanas e não-humanas, que o apreendem segundo pontos de vista distinto" (1996, p. 116).

Dessa forma, as sociedades ameríndias vivenciam uma visão multinaturalista, na qual existe uma cultura e múltiplas naturezas. Nesse caso, trata-se da cultura humana, e esta convive com muitas naturezas e todas são vivas, pensantes, vivas e sobretudo portadoras de cultura. Para Aparecida Vilaça, o corpo é "o lugar da personalidade, é o que define a pessoa, animal, planta ou coisa. Tudo o que existe tem um corpo, uma substância, que é o que lhe dá características." (2000, p. 59).

No cenário etnográfico sul-americano as noções de pessoa e de corporalidade se fazem centrais para a compreensão da organização social. Isso se torna evidente no trecho a seguir:

"Os Wari' costumam dizer: "Jekwere" ("meu corpo é assim”), que significa: "esse é meu jeito", "eu sou assim mesmo". E também quando se referem a animais ou coisas. Se perguntamos a eles por que as queixadas andam em bando, eles dirão: "Jekwereinmijak" ("o corpo da queixada é assim"); ou por que a água é fria: "Jekwereinkom" ("ocorpo da água é assim")" (VILAÇA,2000, p. 59).

Para Seeger, Da Matta e Viveiros de Castro "a noção de pessoa é uma consideração do lugar do corpo humano na visão que as sociedades indígenas fazem de si mesmas" (1974, p.3). Tal estudo possibilita a compreensão correta da organização sócio-cosmológica dessas sociedades.

Segundo os mesmos autores, contrariando as noções ocidentais, o corpo ameríndio não é um suporte único de identidade. Existem também "os complexos denominação, grupos identidade cerimoniais, as teorias sobre a alma associam-se a construção do ser humano tal como entendida por diferentes grupos tribais". Para Viveiros de Castro (1974, p.4) "o corpo afirmado ou negado, pintado e perfurado, resguardado ou devorado, tende sempre a ocupar a posição central na visão das sociedades indígenas.". 
Dessa forma, o corpo não é visto como um suporte de identidade e papéis sociais, mas como uma matriz de símbolos e um objeto de pensamento. A construção do corpo é paulatina e fala sobre as formas de construção da pessoa. Nesse trabalho tem-se por objetivo de analisar os relatos de Davi Kopenawa, que foram escritos por Bruce Albert no livro "A queda do céu" para compreender a construção do corpo de um xamã Yanomami.

\section{O mito de origem}

No livro "A queda do céu" (2015), Bruce Albert escreve o discurso de Davi Kopenawa Yanomami. O livro inicia com o desejo de Davi de desenhar as suas palavras nas peles de papel, para que os brancos que moram longe da floresta deixem de ter ideias distorcidas sobre eles. O mito de origem Yanomami conta que nos primeiros tempos, haviam apenas os yarori, eles eram humanos com nomes de animais e estavam sempre se metamorfoseando em caça, até que aos poucos permaneceram na forma de animais.

A primeira floresta também era muito frágil, vivia se transformando, até que o céu caiu sobre ela e os seus habitantes foram arremessados para debaixo da terra e se tornaram vorazes ancestrais de dentes afiados chamados de aõpatari.

Então foi a vez de Omama vir a existir, Omama criou uma floresta mais sólida, criou rios, céu, animais e os Yanomami e seus costumes. Omama tinha um irmão chamado Yaosi, eles viviam sozinhos e nenhuma mulher existia ainda. Certa vez, Omama retirou uma mulher da água, esta veio a ser sua esposa. Ela era um peixe, que se deixou capturar na forma de mulher.

Yaosi não era bonito como Omama, mas tinha a pele coberta de manchas esbranquiçadas, ele era mal e o seu pensamento era cheio de esquecimento. Foi ele que fez surgir na floresta os seres maléficos das doenças e também as epidemias que, assim como ele, são comedoras da carne humana.

Quando Omama ia criar os humanos, Yaosi mudou o material, por isso eles são mortais, e não imortais como Omama desejava. Para combater o malcriado por Yaosi, Omama criou os Xapiris. Os Xapiris fazem com que os Yanomami possam se vingar das doenças e se proteger da morte. Os Xapiris são os espíritos criados por Omama, estes são os espíritos da floresta, espíritos das águas e os espíritos dos animais. 
Apesar de ter criado os Xapiris, ele os escondeu dos homens, até que o seu filho se tornasse xamã. Foi Omama quem o auxiliou nesse processo, ensinou a usar o pó de yâkoana e fazer o chá das cascas das árvores. O filho de Omama escutou as palavras do pai e se concentrou nos Xapiris, entrou em Estado de fantasma e virou outro e então pode contemplar a beleza da dança e das apresentações dos espíritos. Ele foi o primeiro xamã e mandou-lhe segurar o céu, para que não desabe novamente.

\section{A construção de um Xamã}

Nas sociedades indígenas sul americanas a cultura é dada, no sentido de que ela existe e molda os indivíduos. Através dela se dá a fabricação dos corpos, de modo que, a fabricação, decoração, transformação e destruição dos corpos são temas em torno dos quais giram as mitologias, a vida cerimonial e a organização social.

Davi Kopenawa, indígena Yanomami, tinha constantes pesadelos na infância. Mais tarde, quando já era xamã, ele percebeu que os seres que via em seus sonhos eram os xapiri. Segundo a mitologia Yanomami, Omama é uma divindade criadora, que criou os Xapiris, para que os Yanomami pudessem se vingar das doenças e se proteger da morte. Os Xapiris são os espíritos da floresta, espíritos das águas e os espíritos dos animais.

Quando os Xapiris querem que uma criança seja xamã, eles a observam enquanto ela dorme, isso produz pesadelos e faz com que algumas crianças acordem chorando. Segundo Davi: - "Apenas crianças que veem Xapiris em seus sonhos gritam a noite" (2015, p. 90). Ademais, além dos pesadelos, quando criança, Davi Kopenawa ficava doente com facilidade, pois os seres maléficos da floresta e as epidemias sempre "implicavam" com ele.

Então, cansados de the curar, os xamãs estenderam a imagem de Davi em uma tipoia e esconderam na casa dos espíritos morcegos ou na canoa dos espíritos anta, assim o seu espirito ficava protegido, escondido dos "espíritos ruins que comem a carne humana". Segundo ele: 
com eles enquanto navegava pelas águas, longe dos seres famintos de carne humana. Foi assim que eu finalmente parei de ficar doente com tanta frequência" (KOPENAWA \& ALBERT, 2015, p.96)

O mito de origem narra que Yaosi, o irmão de Omama, tinha o pensamento cheio de maldade. Foi ele que fez surgir na floresta os seres maléficos das doenças e também as epidemias que, assim como ele, são comedoras da carne humana. As vezes os Xapiris fixam os seus olhos nas crianças só porque elas bebem muito mel. O mel é o alimento preferido dos espíritos e quando as crianças o tomam muito, os Xapiris aparecem muito em seus sonhos.

Ter pesadelos e ficar doente com facilidade são os primeiros indícios de que os Xapiris se agradaram da criança. Todavia, para que esta venha a se tornar $m$ Xamã ou, em outras palavras, para que a construção do corpo xamãnico não seja interrompida, é necessário cumprir prescrições e evitar tabus sexuais e alimentares.

Os espíritos se sentem enojados com o cheiro do órgão sexual masculino por isso, para ser xamã, é necessário resguardar-se de pensar e ter relações sexuais prematuras. Se os rapazes começarem a iniciação sexual precoce, o odor dos fluidos espantará os espíritos.

Na infância as crianças podem sonhar e entrar em "estado de fantasma". Tal estado permite ao indivíduo ver os demais seres que habitam o mundo e interagir com eles, como se fossem membros de outras aldeias. Porém para ser xamã e conhecer os Xapiris de verdade, é necessário tomar o chá da yãkoana por muito tempo. "É assim que alguém se torna de fato um homem espirito" (KOPENAWA \& ALBERT, 2015, p.101).

Segundo o mito de origem, foi Omama, a divindade criadora, quem ensinou a usar o pó de yâkoana e fazer o chá das cascas das árvores para fazer dançar os Xapiris. O filho de Omama escutou as palavras do pai e assim tornou-se o primeiro xamã.

As mulheres também podem ser Xamãs. Davi Kopenawa conta que a sua filha também tinha pesadelos na infância e entrava com facilidade em "estado de fantasma", definido com o momento em que a pessoa consegue perceber os animais, plantas e outros seres não-humanos como se fossem humanos, como seres possuidores de cultura. Os Xapiris gostavam dela, e ela tinha interesse em beber a yãkoana mas ao crescer, logo se casou. Segundo Ele: 
"Mas, agora, ela é adulta e está casada. Talvez ainda sonhe com os espíritos, mas não fala mais nisso. Seu pensamento está ocupado com muitas outras coisas" (KOPENAWA \& ALBERT, 2015, p.97)

Embora a filha de Davi Kopenawa possuísse os pré-requisitos, o fato de não ter esperado a sua transformação em xamã estar completa para depois constituir uma família, interrompeu o processo de formação do corpo.

Davi conta que, na infância, ele temia as mulheres e sempre procurava se manter longe delas, pois o cheiro das folhas que ornamentavam os seus braços afugentavam os espíritos. Por isso, ele andava bastante pela floresta, concentrado na caça. E a noite os espíritos ancestrais se apresentavam a ele em sonhos com suas danças. Davi Kopenawa ao se referir aos espíritos animais como "espíritos ancestrais" faz alusão ao mito de origem Yanomami, que conta que nos primeiros tempos, haviam apenas os yarori, eles eram humanos com nomes de animais e estavam sempre se metamorfoseando em caça, até que aos poucos permaneceram na forma de animais.

O padrasto de Davi era um homem sábio e um grande xamã. Ao perceber que os pesadelos aconteciam porque os Xapiris se agradavam de Davi e queriam que ele se tornasse xamã, ele o manteve longe das mulheres e o ensinou a como ser um xamã de verdade. Sempre que o tio e o padrasto de Davi se reuniam com os outros xamãs para afastar os espíritos maléficos, ofereciam a ele o pó da yãkoana. Ele tomava e em pouco tempo entrava em estado de fantasma e via os espíritos dos ancestrais animais, os espíritos da natureza.

O corpo ameríndio não nasce pronto, ele vai sendo construído no decorrer da vida por sua cosmologia. Ele - o corpo - é o local onde a identidade se expressa. No caso dos Wari, esse processo de construção comporta mais de uma identidade, sendo ambas autenticas. Por isso, é possível ser "branco" sem deixar de ser Wari.

No artigo "O que significa tornar-se outro? Xamanismo e contato interétnico na Amazônia”, Aparecida Vilaça percebeu que, devido ao contato, os Wari estavam se apropriando de práticas e do vestuário ocidental. Ao fazer isso, os indígenas assumiam uma dupla identidade: eram brancos e Wari ao mesmo tempo. Segundo ela: 
abandonando os brancos e todas as suas coisas. "Porque somos Brancos", diziam eles". (VILAÇA, 2000, p.53)

Ao serem Wari e branco, esses indígenas vivenciam uma experiência análoga a dos xamãs Wari, que são simultaneamente humanos e animais. O filho de um xamã nasce através do esperma dos Espíritos. Por isso é comum os espíritos se apoderarem deles. Quando isso acontece eles saiam correndo pela mata, se transformavam em "outro" e desapareciam.

Foi assim que aconteceu com o padrasto de Davi. Um dia, quando ele estava na floresta, um ser das águas andou em sua direção e lhe mandou flechar alguns papagaios e ele o fez. Então, o ser segurou o seu braço e disse: "cunhado, está bom! Vou mandar a minha irmã vir buscar suas presas". Logo depois, apareceu uma mulher do povo das aguas e o levou. Ele gritava: "Ae! Ae! Ae!", e aos poucos virou outro.

Passou o dia com o povo das águas e a noite, uma das mulheres o levava para a casa, no dia seguinte tudo recomeçava. Quando isso acontece é necessário que o xamã de sua casa traga de volta a sua imagem para que ele volte a si.

\section{A construção do corpo de Davi Kopenawa}

A construção do corpo xamãnico pode ter início da gestação - no caso dos filhos dos xamãs, que se acredita serem frutos do esperma dos espíritos. Assim eles nascem e tornam-se espirito sozinhos, mas isso só acontece mediante ao resguardo de determinadas regras.

As crianças que não são filhas de xamãs, também podem chegar a ser Xamã. Geralmente, os Xapiris se apresentam as crianças durante a noite, nos sonhos. Além dos pesadelos, as crianças que são olhadas com afeto pelos espíritos, ficam doentes com facilidade por conta da perseguição dos "seres maléficos da floresta e as epidemias" (KOPENAWA \& ALBERT, 2015, p.96).

Para ser xamã é necessário se abster de pensar muito em mulheres, pois se os rapazes iniciarem relações sexuais precocemente os espíritos serão afugentados, e não aparecerão mais em seus sonhos.

Davi sempre era atingido por doenças, então, cansados de Ihe curar, os xamãs 
estenderam a imagem do Davi em uma tipoia e esconderam na casa dos espíritos morcegos ou na canoa dos espíritos anta, assim o seu espírito ficava protegido, escondido dos espíritos ruins que comem a carne humana. E foi assim que ele parou de ficar doente com tanta frequência.

Além disso, para ser xamã é necessário passar bastante tempo na mata, caçando, com o pensamento totalmente voltado para os espíritos. E preciso ter respeito ao caçar, lembrando sempre que o caçador não pode comer da sua caça. A preparação para se tornar xamã também envolve a ingestão de ervas especificas por tempo prolongado. Foi através do sogro e do cadastro de Davi, que também era xamã, que ele passou a beber o yâkoana e o pó de paara.

\section{A relação com o animal na Amazônia}

Segundo Descola (1998), as sociedades ameríndias não vivenciam uma relação de predação da natureza, por isso não compreendem a necessidade das sociedades ocidentais em proteger os animais. Um exemplo disso é dado por Veldan (2008), que suscitou uma importante reflexão: Porque não houve domesticação dos cachorros na Amazônia? Uma vez que haviam cães domésticos (Canis familiaris Linneus) nas terras baixas e na região haviam 12 espécies, distribuídas em 7 gêneros, entre raposas sulamericanas.

A introdução dos cachorros de deu na Amazônia por meio dos colonizadores, e tais animais foram rapidamente incluídos em seu cotidiano devido a sua capacidade de caça. Segundo Veldan (2008), o povo Karitiana tem narrativas curtas e diretas sobre o surgimento dos cachorros, assim como ocorre com todos os demais animais que foram introduzidos pelos "brancos". Segundo o mesmo autor:

\footnotetext{
"Dizem os Karitiana que esses seres "não têm história", no sentido de que a respeito deles não existem relatos míticos que descrevam suas origens no tempo pretérito distante que os índios denominam, em português, "tempo [de] antigamente": "cão não foi Deus [Botyî] que criou", nas palavras de Epitácio Karitiana. (VELDAN, 2008, P.7)
}

Os cachorros e são tidos como estrangeiros. Dentre os Karitiana, eles pertecem a uma família. Quando são filhotes ou muito idosos os cachorros recebem o mínimo de cuidados, por parte das mulheres, mas na fase adulta são responsáveis por si mesmo. 
Segundo o mesmo autor:

"Embora sejam bastante apreciados como auxiliares de caça, e sejam criaturas bastante próximas dos humanos - ganhando nomes individuais, freqüentemente vivendo e dormindo no interior das residências, e sendo "defendidos" por seus "donos" -, esses indivíduos sofrem as maiores atrocidades por parte dos índios: raramente são alimentados, tendo de procurar comida por conta própria, vivem cobertos de sarna e feridas na pele, são várias vezes surrados por aqueles que estão por perto, e é comum definharem lentamente e morrerem sem qualquer atenção, como vi acontecer mais de uma vez na aldeia Karitiana" (VELDAN, 2008, P.8).

Tais animais possuem uma dupla relação com os humanos, a primeira é de apreciação pela sua capacidade de auxiliar na caça. A segunda relação é de depreciação pelas atitudes consideradas inadequadas. Os Karitiana observam nos cachorros comportamentos que não são aceitos em sua cultura, como por exemplo: serem sujos, comer fezes ou lixo, cometer atos de perversão sexual e incesto, ser agressivos e traiçoeiros.

Além disso, durante a conversão dos Karitiana, na década de 70 por uma missão americana, a palavra diabo acabou sendo associada ao termo "cão", assim, acredita-se que o diabo é o chefe de todos os cachorros, fato que segundo sua cosmologia, explica os maus comportamentos dos cachorros.

Tal contexto foi dado para demonstrar que a relação humano e animal na Amazônia ocorre no sentido de multinaturalismo, onde os animais são pensantes e portadores de costumes. Segundo Veldan (2008) os povos indígenas da Amazônia não domesticaram os animais porque o processo da domesticação animal seria incompatível com as formas de relação que estas culturas concebem entre humanos e os demais seres que povoam o cosmo.

Assim, para Veldan (2008), Descola (1992; 1996; 1998), Viveiros de Castro (1996) e Vilaça (2000) a domesticação do animal envolve um processo de domínio do homem sobre a natureza. Veldan (2008):

"Tais relações não se baseiam na objetivação e na dominação destes por aqueles, mas na premissa de que a subjetividade é um atributo comum aos seres e, portanto, as inter-relações assumem outros contornos diversos do controle da cultura (domesticidade) sobre a natureza (selvageria). Nas terras baixas sul-americanas familiariza-se, mas não se domestica" (VELDAN, 2008, P.13)

Tais processos não fazem sentido dentro da cosmologia ameríndia, onde não 
existe essa oposição entre natureza e cultura. A relação entre homem e animal na Amazônia são relações sociais. Por isto, através de tais pressupostos, pode-se compreender melhor a trajetória de Davi Kopenawa e a construção do seu corpo xamãnico.

\section{Conclusão}

Durante o processo de formação do corpo xamãnico é necessário cumprir prescrições e resguardar tabus alimentares e sexuais. O não cumprimento dessas regras pode comprometer para sempre a formação das identidades. Digo, "das identidades" no plural, porque o xamã possui uma dupla identidade. Ele é "gente" e "espírito" ao mesmo tempo. Essa dupla identidade permite que ele, com o auxílio dos espíritos realize curas de doenças e epidemias.

Como ser "espiritual" capaz de apreender segundo pontos de vista distintos, ele pode garantir a caça e agir como mediador entre humanos e não humanos. Além disso, o xamã possui a função de segurar os céus, para que estes não caiam novamente, como no início, quando Omama criou o mundo. No pensamento ameríndio, o xamã não é uma figura estritamente religiosa ou mística. O processo de garantir a caça e combater doenças e epidemias perpassa as esferas socioeconômicas e atinge a vida sócio-cosmológica.

A caça está intimamente ligada ao papel do xamã, seja caçando durante a sua preparação para ser xamã (ao abster-se de pensar em mulheres, os homens que anseiam em se tornar xamã devem praticar a caça e manter o seu pensamento nas presas) ou preparando caçadores. Davi relata que os antigos xamãs o ornamentavam na infância, com enfeites dos espíritos dos animais. Estes enfeites não eram visíveis aos olhos dos humanos, mas fazia com que os espíritos animais se apaixonassem pelo seu portador, deixando-se capturar por ele.

Segundo Davi: "Os xamãs daquele tempo também me adornaram com os enfeites do espirito anta, para que eu me tornasse um grande caçador". (KOPENAWA \& ALBERT, 2015, p.96). Ao preparar esses adornos para o caçador, o xamã também garante que a sua fome será saciada. Nas palavras de Davi:

"Sem isso, nenhuma anta se deixaria flechar com tanta facilidade, só para aplacar a fome de carne dos anciões! Assim, acho que os xamãs 
amarram esses enfeites nos braços dos meninos para que, mais tarde, cacem para eles, e não lhes falte carne na velhice" (KOPENAWA \& ALBERT, 2015, p. 96).

Em toda a narrativa de Davi Kopenawa se evidencia a relação com o animal e construção do corpo do xamã. Os pesadelos, a abstinência sexual, tabus alimentares, adornos e pinturas constroem o corpo do xamã Yanomami. Corpo esse, que possui duas identidades, de homem e de espirito. O que the permite compreender e respeitar os demais indivíduos que habitam o mundo. Compreender o que os grupos pensam acerca do que os animais pensam, permite-nos compreender a sua estrutura, costumes, tabus, sistemas de parentesco e relação com os "outros".

Geralmente as mulheres das gentes das águas yaWarioma apoderam-se deles e os levam para a sua casa no fundo as águas. Quando são pegos pelas mulheres das águas, os rapazes correm pela mata gritando "Ae! Ae! Ae!”. Eles vão se tornando fantasmas pouco a pouco. Os animais olham para eles e riem, como humanos. As árvores falam com eles e as folhas tocam nele com as mãos.

As gentes das águas são filhos, genros, filhas e noras do sogro de Omama. Eles se parecem com humanos e vivem no fundo dos rios. Eles são grandes caçadores. As suas redes ficam penduradas dentro de casas uma ao lado da outra, no seco, como nas demais aldeias. São eles que os olhos de fantasma das pessoas comuns veem como peixes. No entanto, suas imagens também se tornam xapiri que os xamãs fazem dançar.

Foi assim que aconteceu com o padrasto do Davi, um dia quando ele estava na floresta um ser das águas andou em sua direção e lhe mandou flechar alguns papagaios, ele o fez, então o ser segurou o seu braço e disse: "cunhado, está bom! Vou mandar a minha irmã vir buscar suas presas". Logo depois apareceu uma mulher do povo das aguas e o levou, ele gritava "Ae! Ae! Ae!", e aos poucos virou outro. Passou o dia com o povo das águas e a noite uma das mulheres o levava para a casa, no dia seguinte tudo recomeçava. Quando isso acontece é necessário que o xamã de sua casa traga de volta a sua imagem para que ele volte a si. 


\section{Referências}

CARNEIRO DA CUNHA, Manuela. Os mortos e os outros: uma análise do sistema funerário e da noção de pessoa entre os índios Krahó. Editora Hucitec, 1978.

DESCOLA, Philippe. Estrutura ou sentimento: a relação com o animal na Amazônia. Mana, v. 4, 1998 . p. 23-45. Acesso em 13 de janeiro de 2016. Disponivel em: http://www.scielo.br/scielo.php?pid=S0104-93131998000100002\&script=sci_arttext

KOPENAWA, Davi; ALBERT, Bruce. A Queda do Céu: palavras de um xamã yanomami. 2015.

LÉVI-STRAUSS, Claude. 1955. Tristes Tropiques. Paris: Plon, 1976

MAUSS, Marcel. Uma categoria do espírito humano: a noção de pessoa, a de "eu". Sociologia e antropologia, p. 367-397, 2003.

SEEGER, Anthony; DA MATTA, Roberto; DE CASTRO, Eduardo Batalha Viveiros. A construção da pessoa nas sociedades indígenas brasileiras. Rio de Janeiro, Museu Nacional, 1979.

VELDEN, Felipe V. Sobre cães e índios: domesticidade, classificação zoológica e relação humano - animal entre os Karitiana. Avá, n. 15, p. 00-00, 2009.

VILAÇA, Aparecida. 1992. Comendo como Gente: Formas do Canibalismo Wari? (Pakaa Nova). Rio de Janeiro: Anpocs/Editora UFRJ.

VILAÇA, Aparecida. O que significa tornar-se outro?: Xamanismo e contato interétnico na Amazônia. Revista Brasileira de Ciências Sociais, 2000. P. 54 -72.

VIVEIROS DE CASTRO, Eduardo. 1977. Indivíduo e Sociedade no Alto Xingu: Os Yawalapíti. Dissertação de Mestrado, PPGAS/Museu Nacional/ UFRJ.

VIVEIROS DE CASTRO, Eduardo; BATALHA, Eduardo. A fabricação do corpo na sociedade xinguana. Sociedades Indígenas \&Indigenismo no Brasil. Org João Pacheco de Oliveira Filho. RJ: Marco Zero, 1987.

VIVEIROS DE CASTRO, Eduardo. Os pronomes cosmológicos e o perspectivismo ameríndio. Mana, v. 2, 1996. P 115 - 144. Acesso em 13 de janeiro de 2016. Disponivel no site: http://www.scielo.br/scielo.php?pid=S0104-93131996000200005\&script=sci_arttext 